\title{
The Role of Activin-A in the Etiopathogenesis of Nasal Polyposis
}

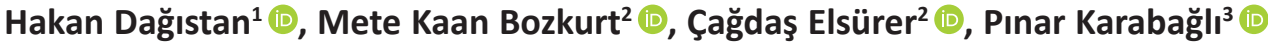 \\ ${ }^{1}$ Yozgat Bozok University, Faculty of Medicine, Department of Otorhinolaryngology-Head and Neck Surgery, Yozgat, Turkey \\ ${ }^{2}$ Selcuk University, Faculty of Medicine, Department of Otorhinolaryngology-Head and Neck Surgery, Konya, Turkey \\ ${ }^{3}$ Selcuk University, Faculty of Medicine, Department of Pathology, Konya, Turkey
}

ORCID ID: H.D. 0000-0003-4717-5337; M.K.B. 0000-0002-3153-3294; Ç.E. 0000-0001-9804-7023; P.K. 0000-0002-5558-0175

Citation: Dagitan H, Bozkurt MK, Elsurer C, Karabagli P. The role of activin-a in the etiopathogenesis of nasal polyposis. Tr-ENT 2021;31(3):60-65. https://doi.org/10.26650/Tr-ENT.2021.994774

\section{ABSTRACT}

Objective: Nasal polyposis (NP) is defined as persistent inflammation of the sinonasal mucosa intractable to medical and surgical treatment. Activin-A, is a pleiotropic cytokine in the transforming growth factor-b (TGF- $\beta$ ) superfamily and was shown to orchestrate the allergic inflammation in asthma via suppression of T helper-2 (Th2) cells, induction of regulatory T cells, and tissue repair. The purpose of this study was to investigate the role of the activin-A in pathophysiology of NP.

Materials and Methods: According to the European Rhinosinusitis and Nasal Polyp criteria, 50 patients and 24 healthy subjects were included in the study. There were no significant differences across age and gender between the 2 groups ( $p>0.05$ ). Samples from patients with NP ( $n=50 ; 11$ women, $39 \mathrm{men}$ ) were acquired during endoscopic sinus surgeries. Middle turbinate specimens from patients without sinus disease and who were undergoing septoplasty were collected as controls ( $n=24 ; 3$ women, 21 men).

Results: Immunohistochemical staining with activin-A showed an increase in the staining intensity, number of glands and inflammatory cells in polyp specimens compared to healthy nasal mucosa. In contrast, no differences were found in fibroblasts and vascular density.

Conclusion: We evaluated the expression of activin-A in NP tissue, which showed a slightly elevated expression compared to the controls. This might support the possible role of activin-A in the pathophysiology of NP. Clearer elucidation of the roles of activin-A and other mediators in tissue remodeling in NP may ensure more accurate targets for treatment and prevention of relapse.

Keywords: Activin A, Nasal polyps, Sinusitis, TGF- $\beta$

\section{INTRODUCTION}

Nasal polyposis (NP) is a severe chronic inflammatory disease of the nasal and paranasal mucosa characterized by semitranslucent, gelatinous, pale mucosal outgrowths that typically originate from the middle meatus and major symptoms are nasal congestion, nasal obstruction and anosmia or hyposmia. It affects up to $4 \%$ of the population, is slightly more common in men and has a high recurrence rate (1). NP is frequently associated with chronic rhinosinusitis and asthma $(2,3)$.

Histopathologically, nasal polyps are characterized by epithelial shedding, basement membrane thickening, subepithelial edema, albumin deposition, pseudocystic formations and vascular/glandular atrophy with T helper-2 (Th2) skewed eosinophilic inflammation (4).

The belief of "one airway, one disease" is widely known and accepted all over the world. Asthma and NP have actually the same inflammatory properties, including infiltration of eosinophil, hyperplasia of goblet cell, a Th2-cell immune response, and tissue remodeling. (5). The airway epithelium can release many chemokines, cytokines and growth factors, which regulate inflammation and remodeling (6).

Among these cytokines, transforming growth factor- $\beta 1$ (TGF- $\beta 1$ ) plays a strong role in asthma pathogenesis due to its ability to inhibit airway hyperresponsiveness and promote airway remodeling $(6,7)$. TGF- $\beta 1$ has also been shown to play

Corresponding Author: Hakan Dağıstan E-mail: hdagistan@yahoo.com

Submitted: $13.09 .2021 \bullet$ Accepted: 05.10.2021 • Published Online: 18.10.2021

This work is licensed under Creative Commons Attribution-NonCommercial 4.0 International License. 
a key role in chronic rhinosinusitis-related tissue remodeling processes in the mucosa, through promoting the differentiation of fibroblasts into myofibroblasts and increasing the production of extracellular matrix proteins (8). However, the role of TGF- $\beta 1$ in NP is still controversial with increased expression in some immunohistochemical studies and lower TGF- $\beta$ levels in others $(5,9)$.

Activin-A is a pleiotropic cytokine belonging to the inhibin activin family within the TGF superfamily of dimeric molecules and uses homologous signal transmission path as TGF- $\beta 1$, including Smad-dependent and Smad-independent pathways (10). It has a regulatory role in many processes such as embryological development, immune system, hematopoiesis and cell regeneration (11). TGF- $\beta$ and activin signaling pathways are activated in allergic pulmonary diseases and airway remodeling (12-14). Activin-A promotes human pulmonary fibroblasts and proliferation of airway smooth muscle cells and supplies a connection between acute allergen-specific T-cell responses and chronic TGF- $\beta$-mediated airway remodeling in asthma (13). In this study, it was aimed to evaluate the expression of activin-A in NP samples to investigate its role in the pathogenesis of the disease.

\section{MATERIALS AND METHODS}

Patients who met the European Position Paper on Rhinosinusitis and Nasal Polyps (EPOS) criteria and who agreed to participate were enrolled in the study at the department of otorhinolaryngology of a tertiary hospital (17). The study protocol was approved by the local ethics committee (Ethics committee protocol number: 2012/166). The principles of the Helsinki declaration were followed during the study and written informed consent forms were obtained from all participants. In this study, exclusion criteria were determined according to the EPOS definitions. None of the patients used a course of antibiotics or systemic/local corticosteroids in the 4 weeks prior to the surgery. Samples from patients with NP ( $n=50 ; 11$ women, 39 men) were acquired while endoscopic sinus surgeries. Middle turbinate specimens of patients without sinus disease performed septoplasty were gathered as controls ( $n=24 ; 3$ women, 21 men). All samples were fixed in $10 \%$ neutral buffered formalin and stored in paraffin blocks at room temperature.

\section{Immunohistochemistry}

Paraffin-embedded tissue blocks were cut into 5 - $\mu \mathrm{m}$-thick sections. Serial sections from each block were deparaffinized and hydrated to water. Dilute concentrated Diva Decloaker (Biocare, DV2005L2J) at a ratio of 1:19 (1 ml Diva to $19 \mathrm{ml}$ of deionized water). The slides were placed into retrieval solution in Biocare's Decloaking Chamber at $110^{\circ} \mathrm{C}$ for 40 minutes and then the slides were allowed to cool for 20 minutes. Dilute TBS tween solution (TBT999, Scytek) at a ratio of 1:19 ((50 $\mathrm{ml}$ TBS to $950 \mathrm{ml}$ of deionized water). After washing with TBS tween 20, it was treated with 3\% hydrogen peroxide (ACA125, Scytek) for 20 minutes then rewashed twice with TBS tween 20. The Super Blocks (AAA125, Scytek) were incubated for 20 minutes at room temparature. Each section was incubated with the activin-A Receptor Type IC antibody (1;100 dilution) (GTX103442, Genetex) for one hour at room temparature. The slides were washed three times with TBS tween 20 and then were visualized by diaminobenzadine (DAB). Followed by a last wash, the slides were then mounted, coverslipped, and sealed in a solution (ABF125, Scytek) for 20 minutes. The slides were washed three times with TBS tween 20, and incubated using the Sensitek Horseradish Peroxidase Solution (ABF125, Scytek) for 20 minutes. The slides were washed three times with TBS tween 2 , and then were visualized by DAB. The sections were then counterstained with Mayer's hematoxylin (HMM500, Scytek) before dehydration with ethanol and xylene. The slides were then mounted with DDmount (DDKitalia, 04-102) and visualised by light microscopy.

Immunostaining intensity and density of vessels, glandular structures, inflammation and fibroblasts were evaluated using a numerical scoring system ranging from 0 to 3 defined by Muluk et al. (16).

\section{Statistical analyses}

All statistical analyses were performed using SPSS software, version 16.0 (SPSS Inc., Chicago, IL, USA). The Student's t test was used for comparison of age; Chi-Square for comparison of gender and scale between the 2 groups. Data were expressed as medians and interquartile ranges, or in boxand-whisker plots. The Mann-Whitney U 2-tailed test was used for control and NP groups. To determine correlations, the Spearman test was used, and significance was accepted where $p<0.05$.

\section{RESULTS}

The NP group consisted of 39 men (78\%) and 11 women (22\%), whereas the control group had 21 men $(87.5 \%)$ and 3 women (12.5\%). The mean age of the NP group was $42.50 \pm 15.9$ years (range 16-75 years) and $35.92 \pm 13.6$ years in the control group (range 18-64 years) with no statistical significant differences ( $p>0.05)$. The immunohistochemical examination presented in Table 1 showed an increased staining with activin-A antibody ( $p=0.003)$ (Figure 1 ), an increase in inflammatory cells and a decrease in glands ( $p=0.001$ and $p<0.001$ respectively) in the polyp specimens compared to the controls (Figure 2 ). In contrast, no differences were found in fibroblasts and vascular density ( $p=0.87$ and $p=0.12$ respectively) (Figure 3 ).

Table 1: Immunohistochemical examination

\begin{tabular}{lccc}
\hline & Nasal polyposis & Control group & P value \\
\hline Activin-A staining & $3 \pm 0$ & $2.8 \pm 0.4$ & 0.003 \\
Vascular density & $2.5 \pm 0.6$ & $2.7 \pm 0.7$ & 0.12 \\
Glandular density & $1.6 \pm 1.2$ & $2.6 \pm 0.6$ & 0.001 \\
Inflammation & $2.6 \pm 0.6$ & $1.75 \pm 0.6$ & $<0.001$ \\
Fibroblast & $1.6 \pm 0.6$ & $1.58 \pm 0.6$ & 0.87 \\
\hline
\end{tabular}



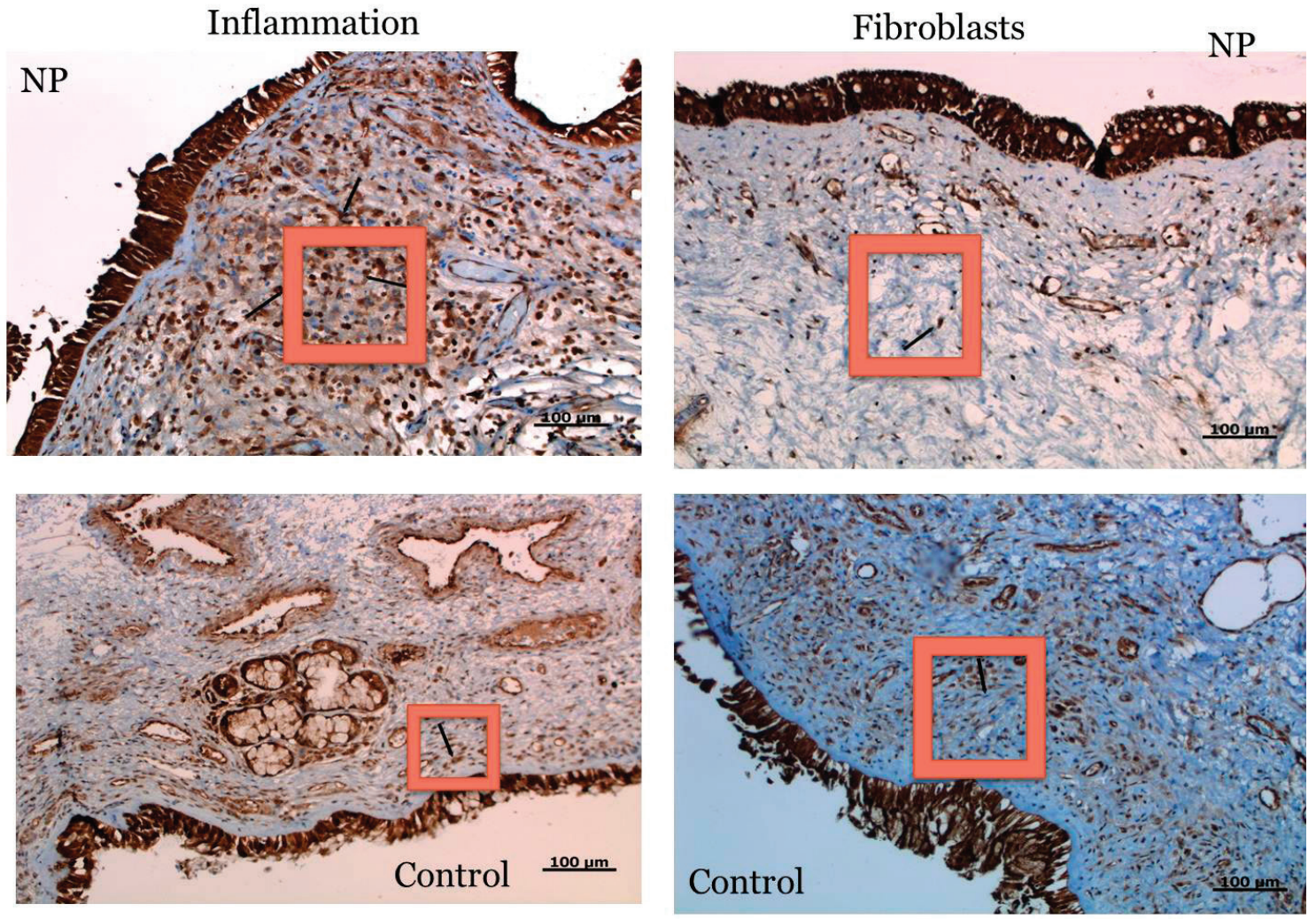

Figure 1: Increased staining with Activin-A antibody in polyp specimens [3+] compared to controls [2+].
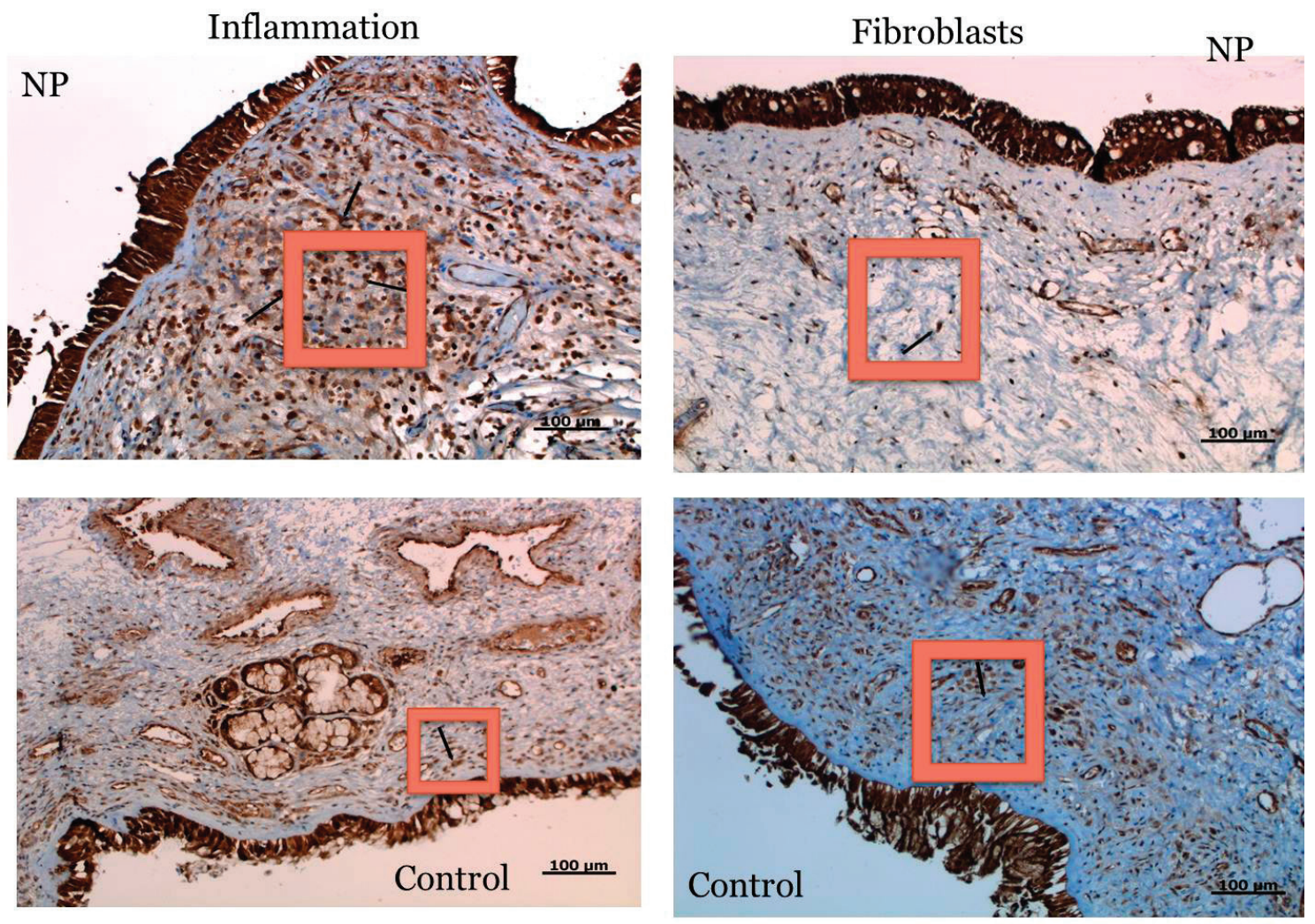

Figure 2: Increase in inflammatory cells and a decrease in glands in polyp specimens compared to controls. 
Vascular density
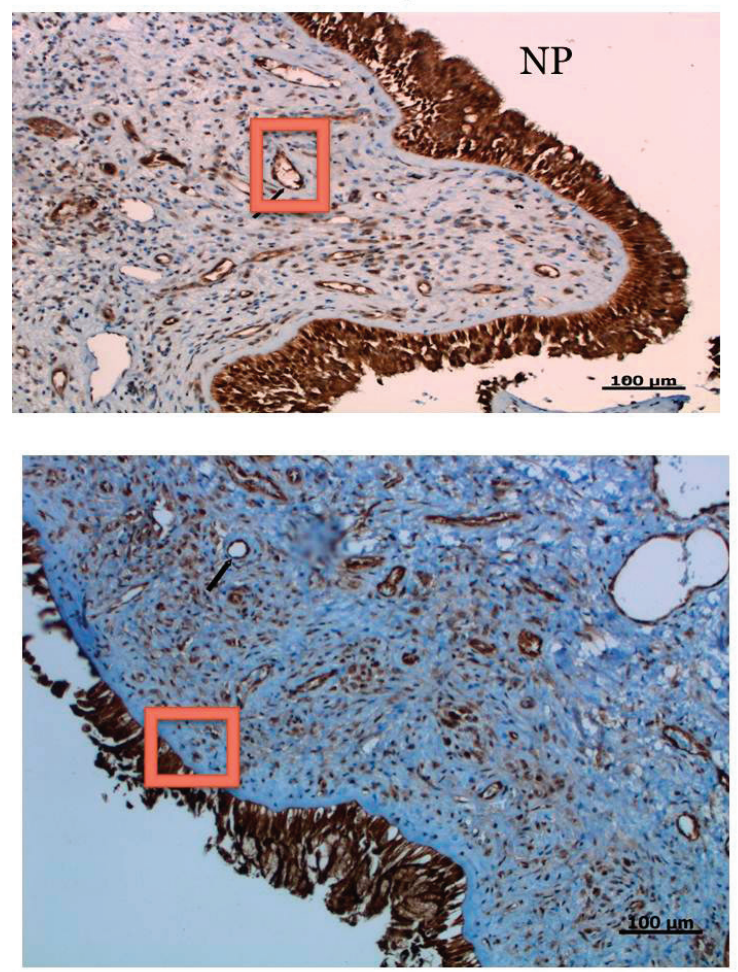

Glandular density
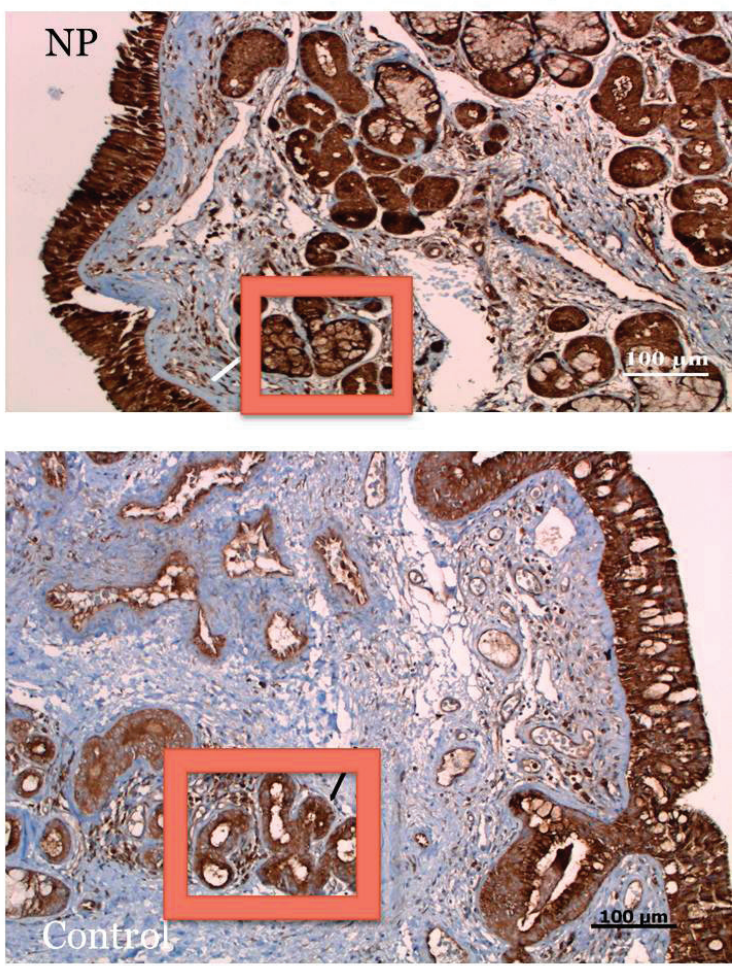

Figure 3: No differences were found in fibroblasts and vascular density in polyp specimens compared to controls

\section{DISCUSSION}

Nasal epithelial repair and remodeling has a remodeling phenomenon similar to the lower airway changes in asthma; It includes inflammation, differentiation, proliferation, and matrix accumulation and regulated by many different growth factors and cytokines (17). Chronic rhinosinusitis is classified into two main subgroups: with and without nasal polyps, which are different clinical conditions depend on different inflammatory mediator and remodeling profiles.

Chronic rhinosinusitis with NP is defined by a predominant Th2-skewed eosinophilic inflammation with high levels of IL5 , eosinophilic cationic protein and eotaxin, and high local IgE concentration in Caucasians and a Th1/Th17 skewed neutrophilic inflammation in Asians $(4,18)$. Huvenne et al. conducted a study in which patients with chronic rhinosinusitis with NP were investigated for inflammatory cytokines simultaneously in samples of the upper and lower airways compared to the control group, and they met higher Th2 levels nasal polyps compared to bronchial samples, there was a strong correlation between upper and lower airway inflammation characteristic (19). Inflammation leads to remodeling in the airway epithelium and several factors such as TGF- $\beta$, matrix metalloproteinases [MMPs], platelet derived growth factor [PDGF] and fibrinolytic components have been implicated in remodeling $(10,20)$. TGF- $\beta 1$ appears to play a key role in tissue remodeling processes in chronic rhinosinusitis in sinus mucosa, through promoting the differentiation of fibroblasts into myofibroblasts, which synthesize extracellular matrix proteins (8). It also influences the balance between MMPs and tissue inhibitors of metalloproteinase (TIMP), which possibly leads to the pathologic tissue remodeling in chronic rhinosinusitis. Wang et al. showed higher expression of TGF- $\beta 1$ and collagen deposition in chronic rhinosinusitis without NP than with NP, in accordance with the former studies (21). There was more severe basement membrane thickening in chronic rhinosinusitis without NP which also confirms the influence of TGF- $\beta 1$ for extracellular matrix production production.

Activin-A, which belongs to the TGF- $\beta$ family, phosphorylates Smad2 and Smad3 from Smad R-Smad) proteins when activated, and this complex translocates into nucleus to activate gene transcription (22).

There is a wealth of data showing that Activin-A promotes inflammation and remodeling in allergic asthma. In an experimental asthma model, mast cells and lymphocytes were shown to secrete activin-A after stimulation by IgE receptor cross-linking or intranasal ovalbumin challenge (23). In another study, its overexpression was shown to induce severe pulmonary inflammation, which was reversed by Activin-A neutralization (24). Smad2 overexpression was found to enhance airway hyperreactivity after intranasal allergen exposure to house 
dust mite extract concomitant with the changes in airway remodeling, such as subepithelial collagen accumulation and hyperplasia of smooth muscle, whereas mice lacking Smad 3 were shown to have decreased peribronchial fibrosis and smooth muscle deposition (13). Interestingly, in some studies, activin-A was shown to be a critical immunoregulator in asthma (25). It induces Foxp3+ regulatory T cells, which suppress T helper cell activity, maintains immune tolerance in the stable situation and inhibits asthma attack (26). The expression and secretion of activin-A in the upper airways are not well known yet. Yang et al. evaluated the level of activin-A and its inhibitor, follistatin, in nasal tissue specimens from chronic rhinosinusitis cases with and without NP, and monitored the spontaneous secretion of these cytokines in a human mucosal model (27). By means of ELISA kits, activin-A, follistatin, TGF- $\beta 1$, and IFN- $\gamma$ concentrations were found to be higher in tissue homogenates from subjects with chronic rhinosinusitis without NP compared to those with NP, while the levels of IL-5 and eosinophilic cationic protein were remarkably lower.

Similar to our study, Chaker et al. collected nasal samples from control turbinate nasal tissue from 48 patients with CRSsNP, during endonasal functional endoscopic sinus surgery as well as from 31 patients without a history of chronic rhinosinusitis during turbinoplasty and septoplasty. They reported a dramatic (48-fold) increase in the frequency of activin-A-producing cells in patients suffering from CRS with NP compared with controls without sinusitis (28). Also Yamin et al. examined the expression of the profibrotic cytokines TGF- $\beta 1$ and activin-A in chronic rhinosinusitis with NP compared to healthy controls and chronic rhinosinusitis without NP sinus or middle turbinate tissue. They showed that TGF- $\beta 1$ and activin-A increased in CRSWNP by immunostaining method (29).

The fact that we did not include cases of chronic rhinosinusitis without NP and did not examine the expression of TGF- $\beta 1$ and activin-A antagonist follistatin, which can provide more information about the inflammatory and fibrotic process in NP, might be considered as a limitation of our study.

\section{CONCLUSIONS}

In this study, we evaluated the expression of activin-A in NP tissue and showed a slightly more elevated expression compared to the controls. While activin-A can't be defined as a specific molecule playing a role in the pathophysiology of nasal polyps, it does seem to be commonly expressed in nasal tissue with inflammation. Clearer elucidation of the roles of activin-A and other mediators in the etiology of NP may provide more effective solutions for treatment and prevention of relapse.

Ethics Committee Approval: The study protocol was approved by Selcuk University Ethics Committee (Ethics committee protocol number: 2012/166), and conducted in accordance with the ethical principles for medical research formulated in the WMA declaration of Helsinki.

Informed Consent: Written informed consent was obtained.

Peer-Review: Externally peer-reviewed.
Author Contributions: Conception/Design of Study- H.D., M.K.B., Ç.E., P.K.; Data Acquisition- H.D., C..E.; Data Analysis/InterpretationH.D., M.K.B., P.K.; Drafting Manuscript- H.D., M.K.B., Ç.E., P.K.; Critical Revision of Manuscript- H.D., M.K.B., P.K.; Final Approval and Accountability- H.D., M.K.B., Ç.E., P.K.;Conflict of Interest: Authors declared no conflict of interest.

Financial Disclosure: Authors declared no financial support

\section{REFERENCES}

1. Stevens WW, Schleimer RP, Kern RC. Chronic Rhinosinusitis with Nasal Polyps. J Allergy Clin Immunol Pract 2016;4(4):565-72.

2. Rajguru R. Nasal polyposis: current trends. Indian Journal of Otolaryngology and Head \& Neck Surgery, 2014;66:16-21.

3. Gelardi M, lannuzzi L, Tafuri S, Passalacqua G, Quaranta N. Allergic and non-allergic rhinitis: relationship with nasal polyposis, asthma and family history. Acta Otorhinolaryngol Ital 2014;34(1):36-41.

4. Cao PP, Li HB, Wang BF, Wang SB, You XJ, Cui YH, et al. Distinct immunopathologic characteristics of various types of chronic rhinosinusitis in adult Chinese. J Allergy Clin Immunol 2009;124(3):478-84.

5. Bachert C, Gevaert P, Holtappels G, Cuvelier C, van Cauwenberge P: Nasal polyposis: from cytokines to growth. Am J Rhinol 2000;14(5):279-90.

6. Hammad H, Lambrecht BN. Dendritic cells and epithelial cells: linking innate and adaptive immunity in asthma. Nat Rev Immunol 2008;8(3):193-204.

7. Alcorn JF, Rinaldi LM, Jaffe EF, van Loon M, Bates JH, JanssenHeininger YM, et al. Transforming growth factor-beta1 suppresses airway hyperresponsiveness in allergic airway disease. Am J Respir Crit Care Med 2007;176(10):974-82.

8. Kou W, Guo-Hua H, Yao H-B, Wang X, Shen Y, Kang H-Y, et al. Regulation of transforming growth factor-1 activation and expression in the tissue remodeling involved in chronic rhinosinusitis. ORL J Otorhinolaryngol Relat Spec 2012;74(3):172-8.

9. Hirschberg A, Jokuti A, Darvas Z, Almay K, Repassy G, Falus A. Pathogenesis of nasal polyposis by immunoglobulin $E$ and interleukin- 5 is complete by transforming growth factor- $\beta 1$. Laryngoscope 2003;113(1):120-4.

10. Yang $\mathrm{Y}$, Zhang $\mathrm{N}$, Lan F, Van Crombruggen $\mathrm{K}$, Fang L, Hu G, et al. Transforming growth factorbeta1 pathways in inflammatory airway diseases. Allergy 2014;69(6):699-707.

11. Hedger MP, Kretser de DM. The activins and their binding protein, follistatin-Diagnostic and therapeutic targets in inflammatory disease and fibrosis. Cytokine Growth Factor Rev 2013;24(3):28595.

12. Gregory LG, Mathie SA, Walker SA, Pegorier S, Jones CP, Lloyd CM. Overexpression of Smad2 drives house dust mite-mediated airway remodeling and airway hyperresponsiveness via activin and IL-25. Am J Respir Crit Care Med 2010;182(2):143-54.

13. Karagiannidis C, Hense G, Martin C, Epstein M, Ruckert B, Mantel $P Y$ et al. Activin $A$ is an acute allergen-responsive cytokine and provides a link to TGF-beta-mediated airway remodeling in asthma. J Allergy Clin Immunol 2006;117(1):111-8.

14. Kariyawasam HH, Pegorier S, Barkans J, Xanthou G, Aizen M, Ying $S$, et al. Activin and transforming growth factor-beta signaling 
pathways are activated after allergen challenge in mild asthma. J Allergy Clin Immunol 2009;124(3):454-62.

15. Fokkens WJ, Lund VJ, Mullol J, Bachert C, Alobid I, Baroody F, et al. EPOS 2012: European position paper on rhinosinusitis and nasal polyps. A summary for otorhinolaryngologists. Rhinology 2012;50(Suppl S23):1-12.

16. Muluk NB, Arikan OK, Atasoy P, Kiliç R, Yalçinozan ET. The role of endothelial nitric oxide synthase (eNOS) in the pathogenesis of sinonasal polyps. Eur Rev Med Pharmacol Sci 2014;18(6):918-29.

17. Yan Y, Gordon WM, Wang DY. Nasal epithelial repair and remodeling in physical injury, infection, and inflammatory diseases. Curr Opin Otolaryngol Head Neck Surg 2013;21(3):263-70.

18. Huvenne W, Van Bruaene N, Zhang N, van Zele T, Patou J, Gevaert $\mathrm{P}$, et al. Chronic rhinosinusitis with and without nasal polyps: what is the difference? Curr Allergy Asthma Rep 2009;9(3):213-20.

19. Håkansson K, Bachert C, Konge L, Thomsen SF, Pedersen AE, Poulsen SS, et al. Airway Inflammation in Chronic Rhinosinusitis with Nasal Polyps and Asthma: The United Airways Concept Further Supported. PLoS One. 2015;10(7):e0127228

20. Van Bruaene N, Bachert C. Tissue remodeling in chronic rhinosinusitis. Curr Opin Allergy Clin Immunol 2011;11(1):8-11.

21. Wang X, Zhao C, Ji W, Xu Y, Guo H. Relationship of TLR2, TLR4 and tissue remodeling in chronic rhinosinusitis. Int J Clin Exp Pathol 2015;8(2):1199-212.

22. Tsuchida K, Nakatani M, Hitachi K, Uezumi A, Sunada Y, Ageta $\mathrm{H}$, et al. Activin signaling as an emerging target for therapeutic interventions. Cell Commun Signal 2009;7:1-11.

23. Cho SH, Yao Z, Wang SW, Alban RF, Barbers RG, French SW, Oh CK. Regulation of activin $A$ expression in mast cells and asthma: its effect on the proliferation of human airway smooth muscle cells. J Immunol 2003;170(8):4045-52.

24. Apostolou E, Stavropoulos A, Sountoulidis A, Xirakia C, Giaglis S, Protopapadakis $E$, et al. Activin-A overexpression in the murine lung causes pathology that simulates acute respiratory distress syndrome. A m J Respir Crit Care Med 2012;185(4):382-91.

25. Hardy CL, Rolland JM, O'Hehir RE. The immunoregulatory and fibrotic roles of activin A in allergic asthma. Clin Exp Allergy 2015;45(10):1510-22.

26. Kariyawasam HH, Semitekolou M, Robinson DS, Xanthou G. Activin-A: a novel critical regulator of allergic asthma. Clin Exp Allergy 2011;41(11):1505-14.

27. Yang $\mathrm{Y}$, Zhang N, Crombruggen $\mathrm{KV}$, Lan F, Hu G, Hong S, Bachert C. Differential expression and release of Activin $A$ and follistatin in chronic rhinosinusitis with and without nasal polyps. PLoS One 2015;10(6):e0128564.

28. Chaker AM, Zissler UM, Poulos N, Wagenmann M, Bas M, Gürth F, Xanthou G, Schmidt-Weber C. Activin-A Is a Pro-Inflammatory regulator in type-2-driven upper airway disease. Int Arch Allergy Immunol 2018;176:15-25.

29. Yamin M, Holbrook EH, Gray ST, Busaba NY, Lovett B, Hamilos DL. Profibrotic transforming growth factor beta 1 and activin $A$ are increased in nasal polyp tissue and induced in nasal polyp epithelium by cigarette smoke and Toll-like receptor 3 ligation. Int Forum Allergy Rhinol 2015;5(7):573-82. 